\title{
Effect of host particle size on the modification of powder flow behaviours for lactose monohydrate following dry coating
}

\author{
Qi Zhou ${ }^{1}$, Brian Armstrong ${ }^{2}$, Ian $\operatorname{Larson}^{1}$, Peter J. Stewart ${ }^{1}$, \\ David A.V. MorTON ${ }^{1 *}$ \\ ${ }^{1}$ Drug Delivery, Disposition and Dynamics, Monash Institute of Pharmaceutical Science, \\ Monash University, Parkville, VIC 3052, Australia \\ ${ }^{2}$ Freeman Technology, Malvern, Worcestershire, UK
}

Received 17 April 2009 - Revised 1st September 2009 - Accepted 22 September 2009 Published online 17 December 2009

\begin{abstract}
Our previous work demonstrated that the powder flowability of a cohesive lactose sample can be improved substantially using a dry coating technique. Our study reported here aims to investigate the influence of host particle size on the modification of powder flowability following dry coating process. Four commercial lactose monohydrate powders with different particle sizes were coated by an intensive mechanical process or mixed using a conventional tumbling process, both with magnesium stearate. All four untreated lactose samples showed a relatively poor powder flow. After dry coating, poured and tapped densities of all the lactose samples increased, while Carr indices and Hausner ratios decreased substantially. The angle of repose values were reduced to a notable extent only for particles with a median size larger than about $7 \mu \mathrm{m}$ after dry coating. Both specific energy (SE) and cohesion values of lactose samples, measured by a powder rheometer system, decreased substantially after coating. In contrast, no apparent changes in powder flow were evident for conventionally mixed batches, except that in the dynamic powder rheometry measurement, a relatively small change in SE was observed. This study demonstrated that for the finer particles examined, cohesive forces were more influential in the powder bed after the surface treatment and resulted in a relatively poor flow. However, for the larger powders studied, the cohesive inter-particle forces could be overcome after this dry coating, whereby satisfactory flow could be obtained. This study indicated that the host particle size was a critical factor in influencing the modification of cohesive powder flowability.
\end{abstract}

lactose monohydrate / dry coating / powder flow / particle size / powder rheometry

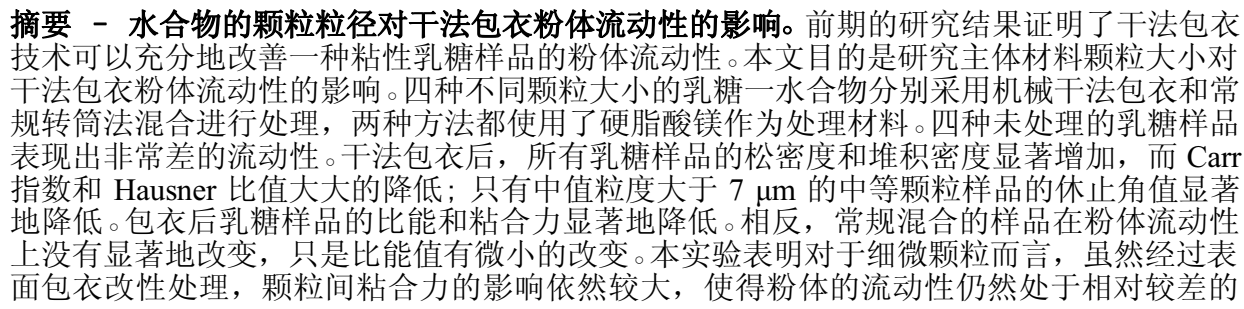

*Corresponding author (通讯作者): david.morton@pharm.monash.edu.au 
水平。然而, 对粒径中等和较大的颗粒干法包衣可以克服颗粒内部之间的粘合力并且获 得满意的流动性。本研究证明了包衣主体材料的粒径是影响粘性粉体流动性改善的主要因 素之一。

\section{乳糖一水合物 / 干法包衣 / 粉体流动性 / 颗粒粒径 / 粉末流变性状测定法}

Résumé - Effet de la taille des particules de poudre de lactose monohydraté sur son enrobage à sec et sur son écoulement. Quatre poudres commerciales de lactose monohydraté ont été enrobées à sec par mécanofusion et mélangées avec du stéarate de magnésium de façon conventionnelle dans un tambour. Avant traitement, les quatre échantillons de lactose non traité présentaient des propriétés d'écoulement relativement faibles. Après enrobage à sec, les masses volumiques, apparente et tassée, de tous les échantillons de lactose augmentaient tandis que les indices de Carr et les ratios d'Hausner diminuaient nettement. Les plus grands changements de masse volumique étaient trouvés pour les échantillons de lactose ayant une taille de particules médiane entre 7 et $20 \mu \mathrm{m}$. L'angle de repos était réduit de façon beaucoup plus importante pour les particules ayant une taille médiane supérieure $7 \mu \mathrm{m}$. L'énergie spécifique et les valeurs de cohésion des échantillons de lactose mesurées à l'aide d'un rhéomètre à poudres diminuaient substantiellement après enrobage. Au contraire, aucun changement apparent dans l'écoulement de la poudre n'était évident pour les lots mélangés en tambour, si ce n'est que, dans les mesures dynamiques de rhéométrie de la poudre, un déplacement limité de l'énergie spécifique était observé. Cette étude démontre que pour les petites particules, les forces cohésives sont influentes dans le lit de poudre, même après traitement de surface et résultent dans un relativement faible écoulement. Cependant, les poudres de plus grosse taille étudiées ont démontré que les forces de cohésion inter-particulaires à l'intérieur de la poudre d'origine pouvaient être surmontées et qu'un écoulement satisfaisant pouvait être obtenu après enrobage à sec. Dans ces séries de poudres de lactose, il a été montré pour la première fois dans cette étude qu'il semble y avoir une taille de particule critique pour laquelle une amélioration fonctionnelle significative de l'écoulement de la poudre peut être obtenue à l'aide de la nouvelle approche d'enrobage à sec. La rhéométrie de la poudre a été démontrée comme étant capable de détecter des différences fines dans le comportement de la poudre à l'écoulement, que des méthodes traditionnelles n'étaient pas capables d'obtenir.

lactose monohydraté / enrobage à sec / écoulement des poudres / taille des particules / rhéométrie des poudres

\section{INTRODUCTION}

Lactose is derived from milk and is widely used in the pharmaceutical industry as an excipient due to its safe and practical properties. Lactose is commonly used as tablet or capsule diluents and as a flow improving carrier in interactive mixtures. Such interactive mixtures are commonly encountered in tablets and in dry powder inhaler formulations [29]. In addition, fine lactose powders can be used as agglomeration modifiers in oral and inhaled powders, but have poor flow properties due to the strong inter-particle cohesive forces $[2,19,33]$. Since poor flow will introduce problems in transportation, mixing, sample filling, compression and packaging of formulations, many studies have been undertaken with the aim to improve the powder flowability of such fine pharmaceutical powders [20, 28, 31, 35].

Dry coating techniques are widely used to improve the flow of cohesive powders by modifying their inter-particle interactions. In general, dry coating is simpler, cheaper, safer and more environment friendly than solvent-based alternatives [8]. "Mechanofusion" is a term used for a recently developed dry coating approach that has gained interest for particle and powder modification [26].

A number of different mechanofusion systems are available, but in general they consist of a cylinder chamber and a process head that rotate relative to each other at high 
speed to create intense shear and compression of the core (host) and coating (guest) particles both via impaction with the face of the process head and via compression as the particles are pushed between the edge of the head and the chamber wall. The process head will consequently break up agglomerates of the cohesive particles to expose their surfaces as the process head rotates at high speed, a considerable amount of thermo-mechanical energy is generated which coats the guest material onto the exposed surfaces of the host particles [4, 25]. Although the particle interactions and kinetic energy exchanges in the mechanofusion process have been studied using simulation and modelling tools, the mechanism of mechanofusion for different materials appears complex and is not well understood $[11,12,26]$. However, unlike general milling and co-milling processes, the energy input is more controlled because the process head geometry, speed and gap from the wall are fixed, and the process can be tuned to encourage coating but not size reduction [24].

Mechanofusion is used in a wide variety of applications. Its ability to engineer particles is exploited to modify a range of their physico-chemical properties. Flowability of some poor-flowing powders has been reported to be improved dramatically after mechanofusion. For example, $5 \mu \mathrm{m}$ polymethylmethacrylate (PMMA) particles coated with $10 \%(\mathrm{w} / \mathrm{w})$ of $0.015 \mu \mathrm{m} \mathrm{TiO}_{2}$ particles using mechanofusion were reported to flow so freely that they appeared to possess a near-zero angle of repose (AOR). In contrast, both the original PMMA and $\mathrm{TiO}_{2}$ particles had poor flow properties [36]. Similar findings are also reported when micron-sized PMMA is mechanofused with nano-sized $\mathrm{TiO}_{2}, \mathrm{Al}_{2} \mathrm{O}_{3}$ or $\mathrm{SiO}_{2}$ particles [18]. Processing of ground polystyrene resin of $10 \mu \mathrm{m}$ size with carbon black via mechanofusion was also demonstrated to produce an easily flowing toner material of rounded shape [36]. Dry coating of corn starch with different silica particles also showed a dramatic improvement in powder flow reflected by lower angles of repose values [35].

In our earlier investigations, powder flow has been improved significantly after mechanofusion treatment of a lactose monohydrate milled powder with a median particle size of $\sim 20 \mu \mathrm{m}$ [37]. It has been well known that the particle size is a key factor in powder flowability $[10,13,16]$. Thus in the present study, the role of the particle size of the lactose monohydrate in the improvement of powder flow following dry coating has been investigated. More specifically, the work was intended to identify the minimum size in this lactose system whose powder flow can be improved using the dry coating technique. A set of four commercially available cohesive $\alpha$-lactose monohydrate (in short, lactose) samples, which have relative small particle sizes and poor flowability, were coated with magnesium stearate as an inter-particle force modifying agent via mechanofusion. All samples were also mixed with magnesium stearate using a conventional tumbling method. The powder flow properties of untreated and treated samples were then characterized using both traditional methods and a set of more recent techniques based on powder rheometry and shear testing.

\section{MATERIALS AND METHODS}

\subsection{Materials}

Four $\alpha$-lactose monohydrate samples were used in this study. Pharmatose ${ }^{\circledR} 450 \mathrm{M}$ (P450) and Pharmatose ${ }^{\circledR}$ 350M (P350) were donated by DMV International, Veghel, The Netherlands. Sorbalac ${ }^{\circledR} 400$ (S400) was obtained from Meggle $\mathrm{GmbH}$, Wasserburg, Germany and Lactohale ${ }^{\circledR}$ LH 300 (L300) from Friesland Foods Domo, Zwolle, The Netherlands. Magnesium stearate NF (MgSt) was supplied by Mallinckrodt Chemicals, Phillipsburg, USA and 
propan-2-ol from Honeywell Burdick \& Jackson, Muskegon, USA. All samples were used as received.

\subsection{Methods}

\subsubsection{Dry coating and tumbling mixing of cohesive powders}

Dry coating of lactose samples with $\mathrm{MgSt}$ was carried out in a mechanofusion system (Nobilta-130, Hosokawa Micron Corporation, Osaka, Japan). Prior to mechanofusion treatment, lactose samples $(\sim 100 \mathrm{~g})$ were manually premixed with a level of MgSt that was estimated to be a minimum that could be used to provide a complete covering ( $2 \%$, $2 \%, 1 \%$ and $1 \% \mathrm{w} / \mathrm{w}$ for L300, S400, P450 and P350 respectively) [24]. Then, the mixtures were poured into the process vessel (process volume $=1 \mathrm{~L}$ ). The mechanofusion processing was performed for $10 \mathrm{~min}$ at $5000 \mathrm{rpm}$ in order to coat the MgSt onto the host lactose particles. Cold water was circulated through the incorporated water jacket to prevent the vessel temperatures from exceeding $25^{\circ} \mathrm{C}$.

Conventional blending of lactose with the same content of MgSt as in the mechanofusion studies was also carried out using a Turbula ${ }^{\circledR}$ T2F mixer (Glen Mills Inc., Clifton, USA). Lactose samples $(\sim 20 \mathrm{~g})$ and additives were weighed into a glass container that was approximately a quarter full. The container was then fixed in the mixer and tumbled for $30 \mathrm{~min}$ at $72 \mathrm{rpm}$.

\subsubsection{Scanning electron microscopy}

Scanning electron microscope (Phenom ${ }^{\mathrm{TM}}$, FEI Company, Hillsboro, Oregon, USA) was employed to examine the morphology of the lactose samples. Each sample was poured onto a double-sided carbon black tape that was mounted on a sample holder. Samples were sputter coated with gold using an electrical potential of $2.0 \mathrm{kV}$ at $25 \mathrm{~mA}$ (SCD005, BAL-TEC AG, Balzers,
Germany). Scanning electron microscopy (SEM) micrographs were taken using the in-built image capture software.

\subsubsection{Powder bulk densities and derived indices}

The poured density $\left(\rho_{p}\right)$ was measured by pouring the samples slowly into a $10 \mathrm{~mL}$ measuring cylinder via a funnel at a fixed height. The tapped density $\left(\rho_{t}\right)$ was determined after 1250 taps of an automatic tapper (AUTOTAP ${ }^{\mathrm{TM}}$, Quantachrome Instruments, Boynton Beach, USA). The tapper operated with a $3.18 \mathrm{~mm}$ vertical travel at a tapping speed of $260 \mathrm{tap} \cdot \mathrm{min}^{-1}$. Four replicates were carried out for each measurement.

The Carr index (CI) [9] and the Hausner ratio (HR) [15] were calculated from the poured density and tapped density using the following equations:

$$
\begin{gathered}
\mathrm{CI}=\frac{\rho_{t}-\rho_{P}}{\rho_{t}}, \\
\mathrm{HR}=\frac{\rho_{t}}{\rho_{p}} .
\end{gathered}
$$

\subsubsection{Particle sizing}

The particle size distributions of both original and processed powder samples were measured by laser diffraction (Mastersizer ${ }^{\circledR} \mathrm{S}$, Malvern Instruments, Worcestershire, UK) using the $300 \mathrm{RF}$ lens equipped with a small volume sample presentation unit (capacity $150 \mathrm{~mL}$ ). Approximately $500 \mathrm{mg}$ of lactose powder were sonicated in $20 \mathrm{~mL}$ of propan2-ol in a water bath for $3 \mathrm{~min}$ prior to the measurement. Particle size analysis of each sample was performed using the reference refractive index of lactose (1.533) and propan-2-ol (1.378) [3]. The average particle size distribution was calculated from four replicates of each sample. The average particle size of the primary powders was 


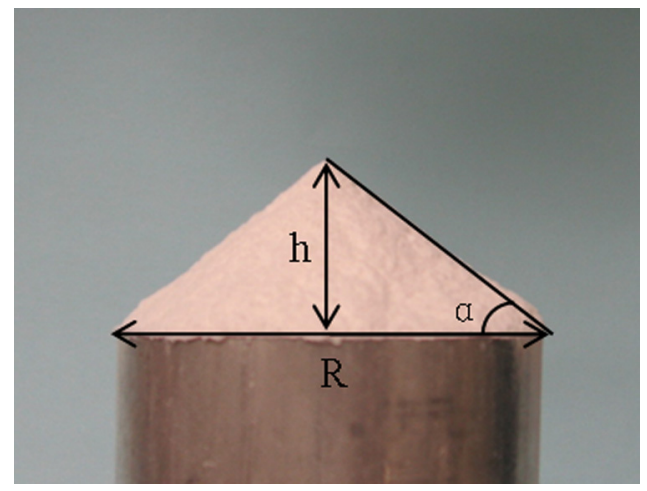

Figure 1. Diagram of the measurement of $\mathrm{AOR}$ ( $h$, height; $R$, diameter; and $\alpha, \mathrm{AOR}$ ).

described by the volume median diameter (VMD).

\subsubsection{Angle of repose}

The AOR was measured as an indicator of powder flowability. The measurement was done according to the guidance in USP 31-NF 26. A sample of $\sim 50 \mathrm{~g}$ was continuously fed through a sieve $(850 \mu \mathrm{m}$ aperture size) and a glass funnel (diameter $=10 \mathrm{~cm}$; length $=10 \mathrm{~cm}$; and stem diameter $=1 \mathrm{~cm}$ ) to form a balanced cone on the flat circular surface of a cylinder aluminium stand (surface diameter $=5 \mathrm{~cm}$ ). The height of the glass funnel was adjusted to stay $2 \mathrm{~cm}$ above the top of the cone, which was found to be important in order to standardize the impact of falling powder on the tip of the cone and so to obtain consistent results. The AOR was defined as the angle between the sides of the cone formed and the horizontal (Fig. 1):

$$
\tan \alpha=\frac{2 h}{R},
$$

where $\alpha$ is the AOR, $h$ is the height and $R$ is the diameter of the cone formed. Four readings for each sample were obtained.

\subsubsection{Powder rheological properties and inter-particle interaction}

Detailed powder flow behaviours, represented by their rheological properties, were characterized using the Freeman FT4 rheometer (Freeman Technology, Worcestershire, UK). Briefly, the powders can be evaluated by measuring their dynamic, shear and bulk properties, using a range of attachments, whilst axial and rotational forces are measured. A number of control/measurement modes are available including position, velocity, force and torque. A more detailed description of the testing methodologies was reported in the literature [13]. In this study, dynamic mode and shear mode were applied to evaluate the powder flow properties and the inter-particle interactions.

In the dynamic mode, a blade with a diameter of $23.5 \mathrm{~mm}$ was traversed through the $25 \mathrm{~mL}$ samples in a $25 \mathrm{~mm}$ diameter glass vessel with a blade tip speed of $100 \mathrm{~mm} \cdot \mathrm{s}^{-1}$ and a helix angle of $-5^{\circ}$. The energy required to move the blade through the powder during an upward traverse was defined as the specific energy (SE). A higher SE value generally represents a poorer powder flow [13]. Conditioning cycles, in which the blade moves upwards to lift the samples with a gentle shear, were used in order to minimize or 
standardize the influence of the stress history on the measurement.

In the shear mode, a shear head was attached to the powder rheometer, and shear stress was measured with respect to the normal stress for a given consolidating stress. A fuller description of the principles of shear cell testing was described by Schwedes [30]. For this application, a consolidating stress of $9 \mathrm{kPa}$ was applied to the powder bed prior to each test. Shear tests were then carried out at normal stresses of 7, 6, 5, 4 and $3 \mathrm{kPa}$. The shear stress at each normal stress was recorded, and yield loci were plotted. The cohesion of each sample was evaluated as the shear stress at zero normal stress by extrapolating the yield loci. The cohesion value thus provides a measure of the cohesive inter-particle forces within the bed, and hence a higher value corresponds to a more cohesive powder [30].

\subsubsection{Statistical analysis}

The statistical analysis of the data derived from different batches of lactose samples was carried out using analysis of variance with Tukey's post hoc analysis at a $P$ value of 0.05 (SPSS version 15.0.0, SPSS Inc., Chicago, IL, USA).

\section{RESULTS AND DISCUSSION}

\subsection{SEM}

Representative SEM micrographs of untreated and processed L300 and P350 are shown in Figures 2 and 3. Images of L300 and P350 were chosen to demonstrate the different morphological properties of relatively smaller and larger groups in this series of lactose powders, respectively. It can be observed from Figure 2a that small particles of untreated batch of L300 with a particle size of about $4 \mu \mathrm{m}$ tend to form larger agglomerates rather than exist as non-agglomerated particles. Only occasionally could non-agglomerated particles be observed for untreated and mixed batches of L300. A higher proportion of nonagglomerated particles are apparent in the micrographs of the mechanofused L300, although many particles are still present as agglomerates (Fig. 2c).

For untreated and mixed P350, fine particles less than about $10 \mu \mathrm{m}$ tended to form agglomerates or are adhered on the surface of larger particles. In contrast, for the mechanofused batch, most of the particles were present as non-agglomerated particles, and very few fine particles can be found on the surface of larger particles (Fig. 2f).

At the higher magnification of $3500 \times$, flake-shaped $\mathrm{MgSt}$ particles appeared to adhere on the large lactose surface, which suggested that the tumbling mixing process was unable to provide enough shear and energy to spread all MgSt onto lactose surfaces (Fig. 3e). At this high magnification, it is quite clear that untreated and mixed batches of P350 exhibit flat smooth surfaces and sharp edges. However, the mechanofused particles have more rounded edges. This can attribute to either attrition during the high-shear processing or coating material covering the sharp edges or both. An undulating surface for the mechanofused batch of P350 contrasts the flat surfaces of the untreated batch and covers almost the whole of the lactose particles mechanofused with MgSt (Fig. 3f). This suggests that the entire surface had been modified and suggests that MgSt may well have been coated across the surface of P350 particles by the mechanofusion. SEM micrographs also showed that the lactose powders were visually better dispersed after mechanofusion treatment as reflected by a greater proportion of non-agglomerated particles and less agglomerates. Repeated measurements confirmed that these differences in dispersion were not due to the sample preparation. 

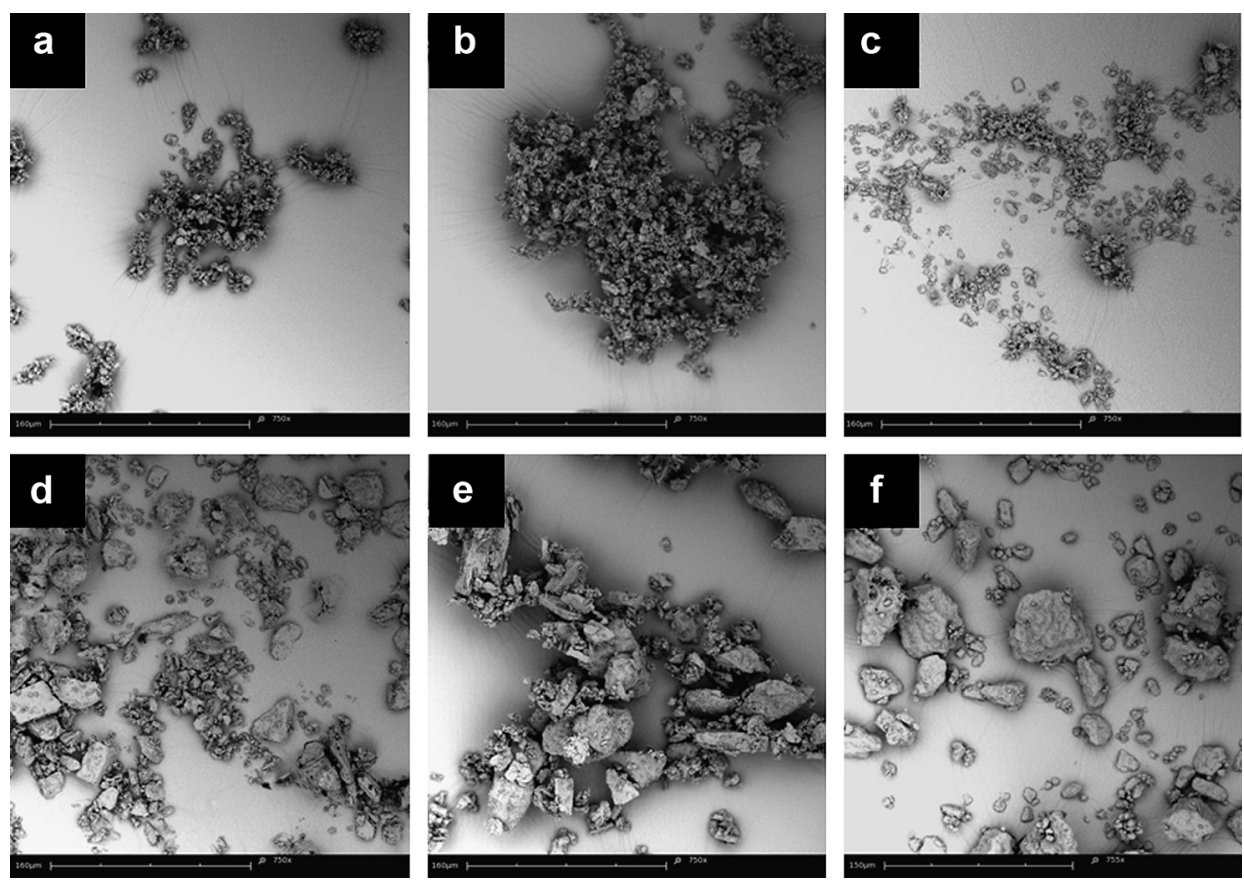

Figure 2. SEM micrographs at a magnification of $750 \times$ of (a) untreated L300; (b) mixed L300; (c) mechanofused L300; (d) untreated P350; (e) mixed P350; and (f) mechanofused P350.

\subsection{Particle size}

Particle size distributions are shown in Figure 4. The VMD value of MgSt was $7.92 \pm 0.70 \mu \mathrm{m}$. The VMD values of untreated samples of L300, S400, P450 and P350 were $3.86 \pm 0.02,6.49 \pm 0.10$, $19.14 \pm 0.20$ and $29.38 \pm 2.12 \mu \mathrm{m}$, respectively, which are significantly different from each other $(P<0.05)$. Consequently, it was considered that these four grades of lactose samples satisfy the objective to investigate the influence of a range of relatively fine particle sizes on their bulk powder flow properties. There are no significant differences in VMD values between untreated and mixed batches of P350 as well as for P450 $(P<0.05)$. A very slight reduction in VMD values was observed for L300 and S400 after mechanofusion treatment
$(P<0.05)$. It was also shown that the untreated lactose samples had very similar particle size distribution patterns to their corresponding mixed and mechanofused batches (Fig. 4).

The particle size results indicate that no substantial changes in particle size were detected after mixing or mechanofusion treatments. These findings are in accordance with those of other reports [22]. It is suggested that any coating layer of MgSt on the surface of lactose particles is too thin to be detected using a laser diffraction technique compared with larger primary sizes of lactose host particles ranging from $\sim 4$ to $30 \mu \mathrm{m}$. Since the mechanofusion process involves intensive high-shear forces, the very slight reductions in particle sizes for L300 and S400 after mechanofusion treatment are possibly due to the attrition during 

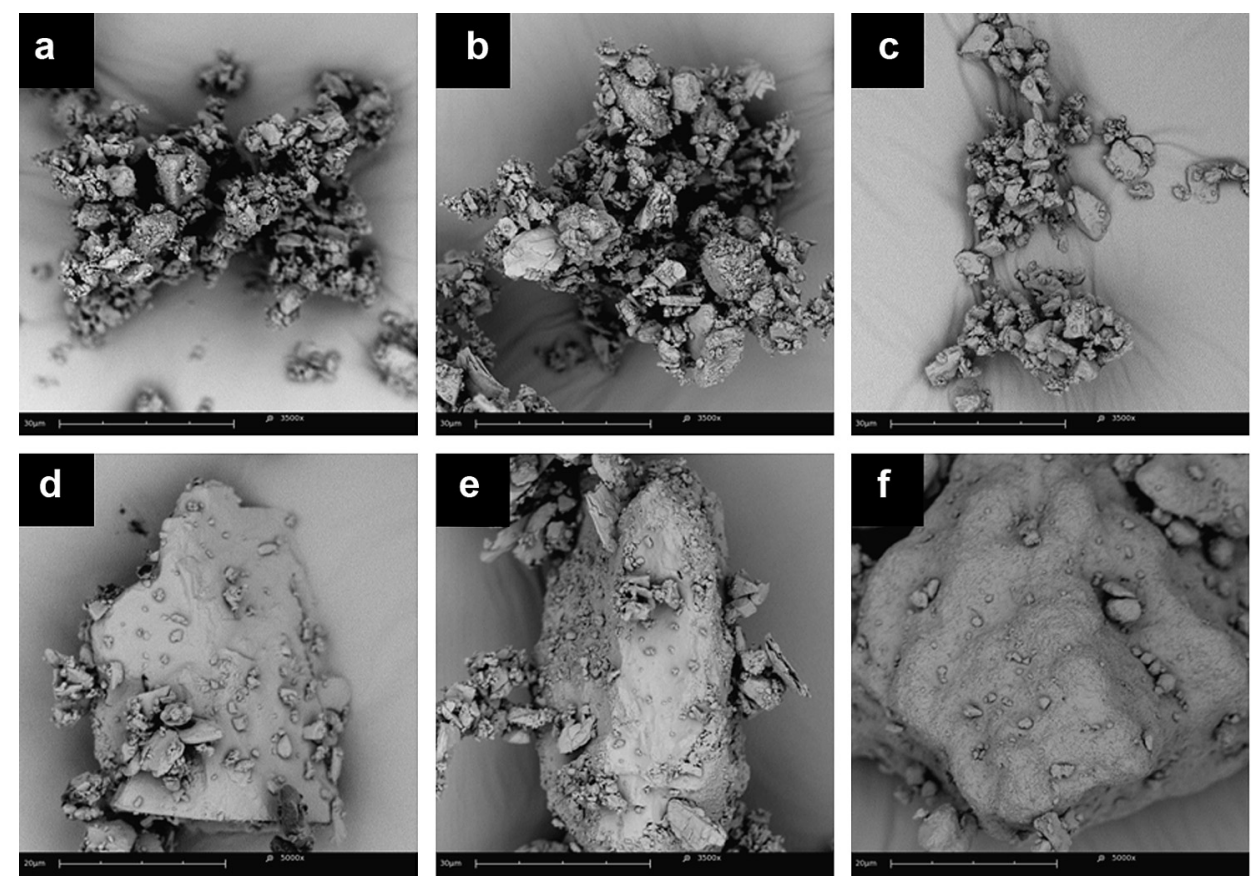

Figure 3. SEM micrographs at a magnification of $3500 \times$ of (a) untreated L300; (b) mixed L300; (c) mechanofused L300; (d) untreated P350; (e) mixed P350; and (f) mechanofused P350.

the mechanofusion processing or alternatively this may be due to improved dispersion and detachment of primary fine particles [5].

\subsection{Powder bulk densities and derived indices}

Both poured and tapped densities increased with the increase of VMD for untreated lactose samples $(P<0.001)$ (Fig. 5). The CI and HR values of untreated P350 that had the largest relative particle size were significantly lower than those of untreated samples of L300, S400 and P450 $(P<0.05)$. However, it was noted that no significant difference was observed in CI and HR values between untreated samples of L300, S400 and P450 $(P>0.05)$, although they had significantly different particle sizes between them. All untreated powders have "very very poor" flow according to the classification system of Carr [9].

No significant difference in poured density was observed between the untreated and the tumbling mixed batches for lactose samples, except P350 $(P>0.05)$. Tapped densities of the untreated batches were found to be significantly higher than those of their corresponding mixed batches for all four grades $(P<0.05)$. Significantly lower $\mathrm{CI}$ and $\mathrm{HR}$ values were observed after tumbling mixing with MgSt for S400 and P450 $(P<0.05)$.

In notable contrast, both the poured density and the tapped density of the mechanofused batches for all four grades of lactose samples were very markedly higher than those of their corresponding untreated or mixed batches $(P<0.001)$. The greatest 


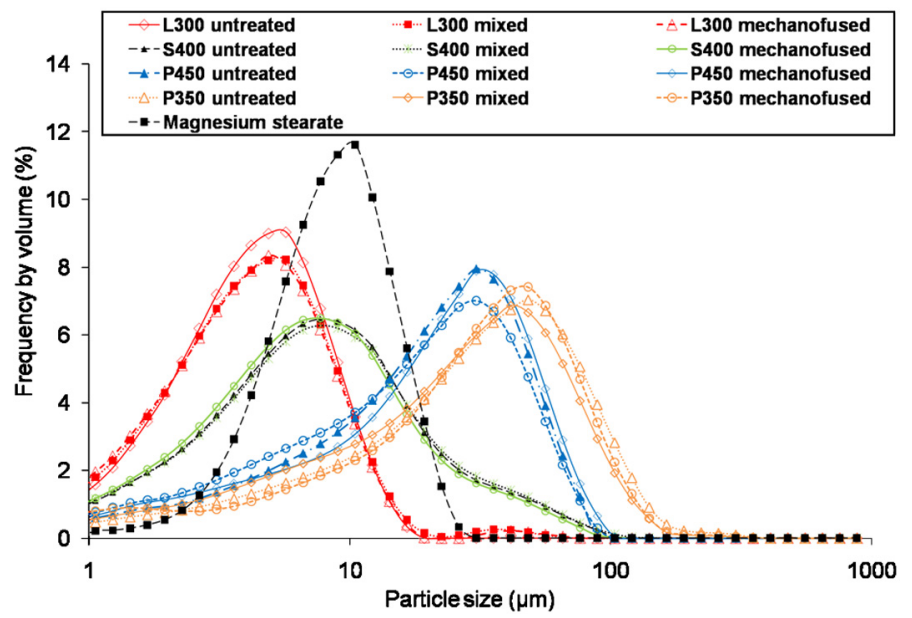

Figure 4. Particle size distributions of lactose and magnesium stearate samples by laser diffraction.
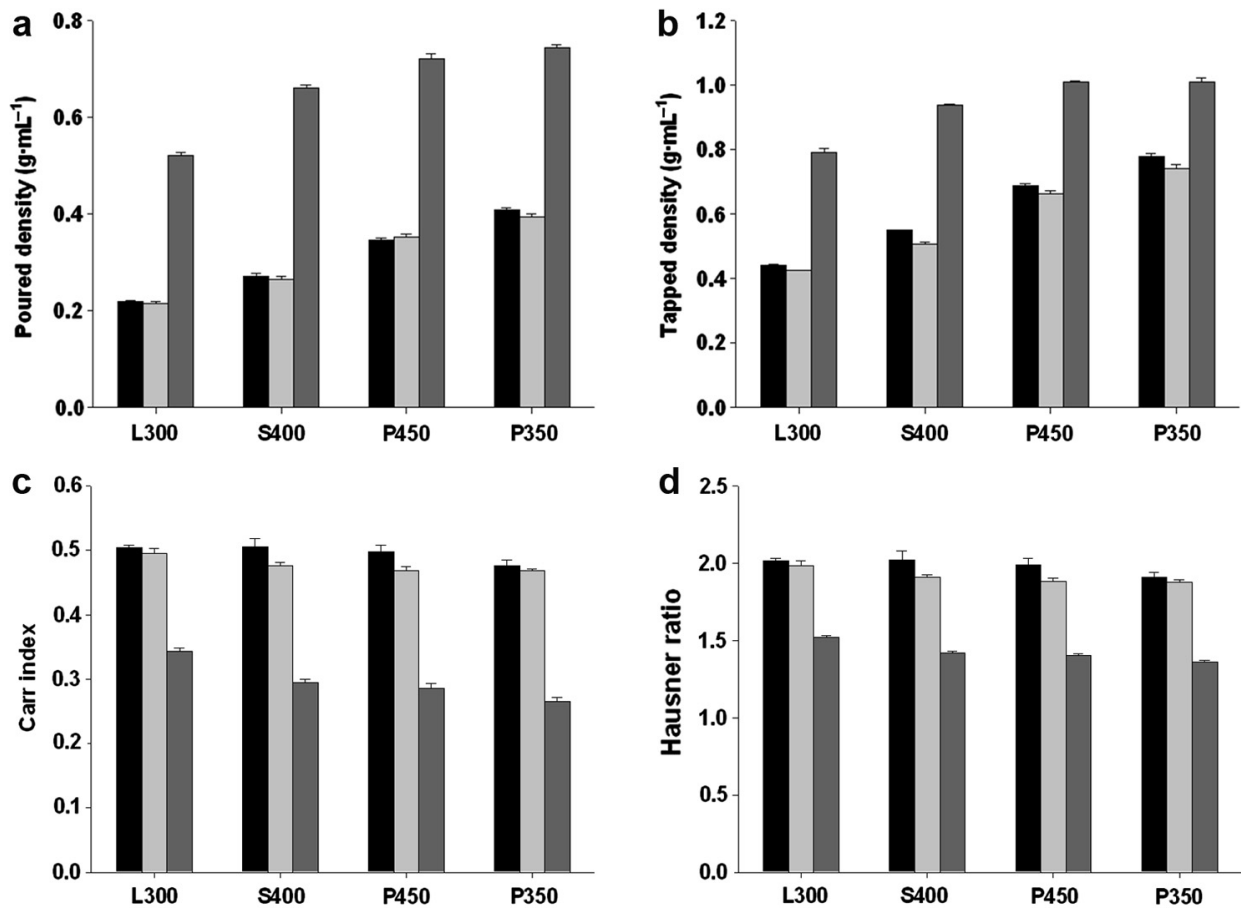

Figure 5. Poured density (a), tapped density (b), CI (c) and HR (d) results of untreated ( $\bullet$ ), tumbling mixed $(\square)$ and mechanofused $(\square)$ lactose samples (mean $\pm \mathrm{SD}, n=4$ ). 
increases between untreated and mechanofused batches in poured density were found for S400 followed by P450, P350 and L300. Both CI and HR values of mechanofused batches were dramatically lower than those of their corresponding untreated batches for all four grades of lactose samples $(P<0.001)$. The $\mathrm{CI}$ values decreased $\sim 32,42,42$ and $44 \%$ after mechanofusion treatment for L300, S400, P450 and P350, respectively.

Powder densities and their derived parameters such as $\mathrm{CI}$ and $\mathrm{HR}$ values are widely used to evaluate powder flowability particularly for cohesive powders $[1,17$, 23, 33]. Generally, non-cohesive powders will be packed more efficiently, and hence have less scope for consolidation and so are not as compressible during a consolidation process such as tapping as a cohesive powder. They consequently exhibit good flowability, which is a key factor during manufacturing. In contrast, cohesive powders are highly compressible and have poor powder flow. When cohesive powders are poured into a cylinder, loose powder bed structures containing a high air volume will be produced due to their high inter-particle forces, especially the van der Waals forces. During the tapping process, this open cohesive bed structure can collapse significantly and rearrange its structure to reduce the voidage, with increase in the number of particle-particle contacts.

In general, the cohesivity of a powder is strongly affected by particle size [10, 14]. For coarse particles, the inter-particle forces are much easier to overcome, compared with fine cohesive particles, and hence they flow freely under gravitational forces. In this study, untreated P350 has higher poured and tapped densities, and better flowability than the powders of untreated L300, S400 and $\mathrm{P} 450$, which contain greater proportions of smaller particles. Our CI and HR results indicated that flowability of these cohesive lactose powders should be improved dramatically after dry coating via mechanofusion. But given that the particle size distributions of our lactose powders did not shift after mechanofusion treatment, these findings suggest that the cohesive inter-particle forces among the lactose particles in the powder beds are much weaker after coating with MgSt. This is in agreement with earlier studies that looked at drug detachment [7].

\subsection{AOR}

The AOR values of lactose samples are listed in Figure 6. The AOR values of all four untreated lactose samples were $>55^{\circ}$ and can be classified as "very poor" powder flow according to Carr's classification $[6,9]$. The AOR values of mechanofused batches were found to be significantly lower than those of their corresponding untreated batches for all four lactose samples $(P<0.001)$. In contrast, no difference was observed in the AOR values between all untreated batches and their corresponding tumbling mixed batches $(P>0.05)$. P450 mechanofused demonstrated the greatest decrease of $37.1 \%$ in AOR values than untreated P450, followed by P350 with a decrease of $33.7 \%$. But the AOR values of L300 and S400 only decreased 5.5\% and $7.1 \%$, respectively, after the mechanofusion processing.

Angle of repose values are a common method for evaluating the flow properties of a powder [6, 10, 27]. In general, $A O R$ values are dependent on the balance between the cohesive inter-particle forces and the particle weight (i.e. gravitational detachment force). Therefore, particle size will play a crucial role in determining the AOR values of a powder. For typical cohesive fine particles $(d \approx 10 \mu \mathrm{m})$, cohesive forces can be four orders of magnitude higher than the particle's weight [34]. Hence, the AOR values will often not distinguish between cohesive fine powders since the cohesive forces will overwhelm gravitational detachment and a similar very 


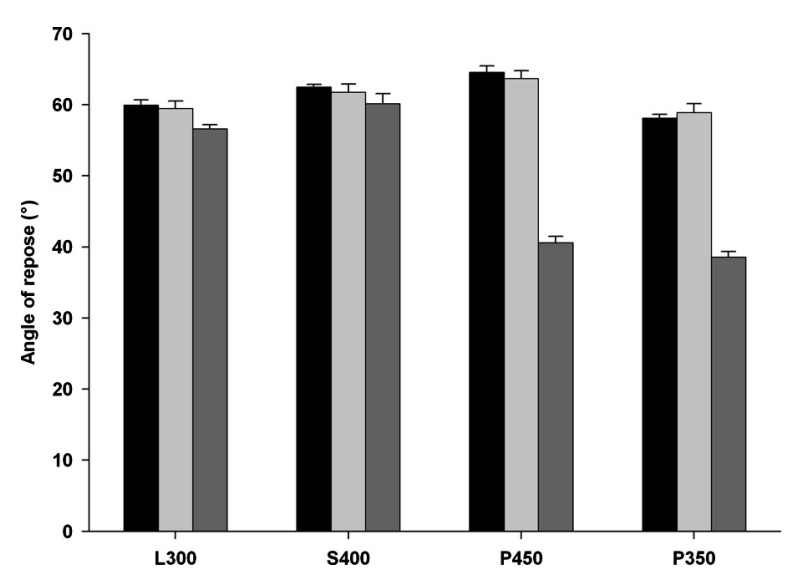

Figure 6. Angle of repose results of untreated ( $\square$ ), tumbling mixed ( $\square$ ) and mechanofused ( $\square$ ) lactose samples (mean $\pm \mathrm{SD}, n=4$ ).

tall cone will be formed for cohesive powders within these different size ranges [10]. In the present study, all the original cohesive lactose powders demonstrated very poor flow, which was reflected by high AOR values $>55^{\circ}$. No meaningful differences were therefore found in the AOR values for all four grades of cohesive untreated lactose powders, despite having significantly different particle sizes. In contrast, after the mechanofusion treatment, the AOR of P450 and P350 was improved dramatically, and this reflected a flowability, which can be deemed as satisfactorily for manufacturing [6].

The improvement in AOR values was much more significant for larger particles with primary median particle sizes of $20 \mu \mathrm{m}$ and over than for smaller particles with primary median particle sizes of $7 \mu \mathrm{m}$ and under. For this lactose powder series, there appears to be a critical particle size range where significant improvement in the AOR values can be achieved by surface modification, which is due to the transition where gravitational forces can overcome the cohesive forces within the powder. In this study, a particle size between the range 7 and $20 \mu \mathrm{m}$ appears to represent such a critical size range for the transition from cohesive to flowable powders, in the case of our surface modification approach.

\subsection{Rheological properties and inter-particle interaction}

Rheological property results of untreated, mixed and mechanofused samples measured by a rheometer are shown in Figures 7 and 8 . The SE values of untreated samples decreased with an increase in primary particle size. The SE value of untreated L300 with primary median particle size of $3.86 \mu \mathrm{m}$ was $10.7 \pm$ $0.8 \mathrm{~mJ} \cdot \mathrm{g}^{-1}$, while that of untreated $\mathrm{P} 350$ with a primary median particle size of $29.38 \mu \mathrm{m}$ was only $5.4 \pm 0.3 \mathrm{~mJ} \cdot \mathrm{g}^{-1}$. There was no apparent difference between untreated batches of L300 and S400 in cohesion value. However, P450 and P350, which have larger particle sizes, showed substantially lower cohesion values than those of L300 and S400.

These rheological results detected using a powder rheometer suggest that powder cohesivity increased with a decrease in particle size which contributes to the poorer flow behaviour of finer powders. These findings are in accordance with those of previous studies [16]. For particles with a similar 


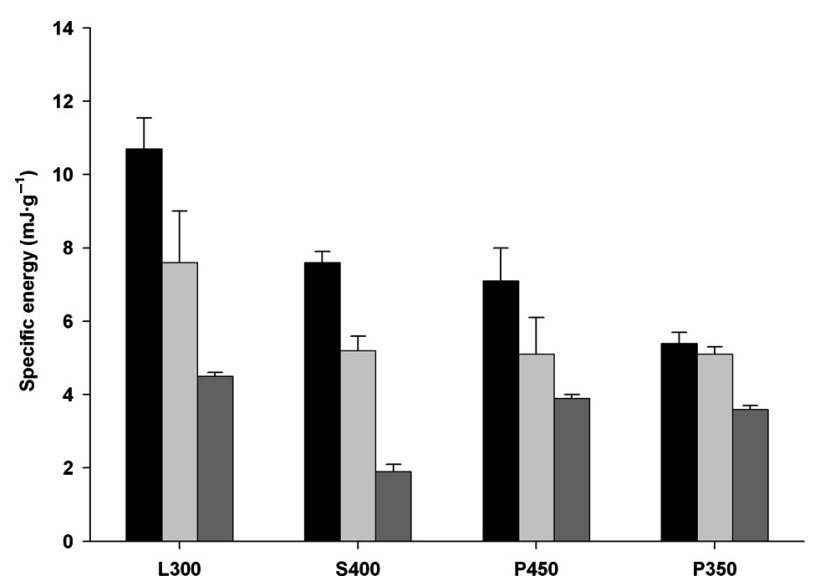

Figure 7. SE results of lactose samples measured by a powder rheometer (mean $\pm \mathrm{SD}, n=4)$.

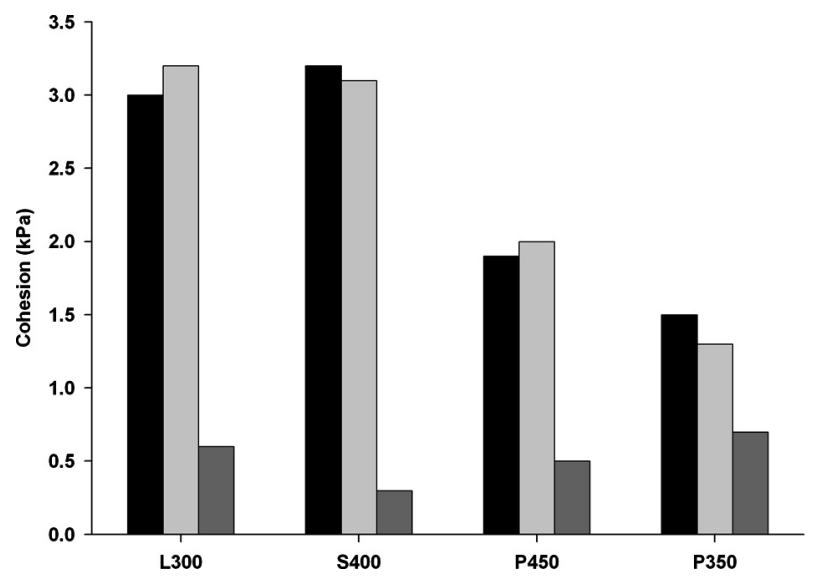

Figure 8. Cohesion results of lactose samples measured by a powder rheometer.

surface structure, smaller particles have larger surface area and higher interfacial surface energy. During powder handling, there are more contacts between smaller particles, which results in a larger contact area per powder mass and stronger cohesive forces. For the powders investigated in this study, they are all cohesive with relative fine particle sizes. The apparent relationship between particle size and flow behaviour for cohesive powders is generally not observed in CI, HR and AOR values. This suggests that densities and AOR methods are not sensitive enough to distinguish differences in powder flow between the cohesive powders in this study. In contrast, dynamic mode powder rheometry is able to detect subtle differences in powder flow between larger and smaller cohesive lactose powders and suggests a relationship 
between particle size and powder flow behaviour.

Significant decreases in SE were found for lactose samples, except P350, after tumbling with $\mathrm{MgSt}$, and the decreases are less for larger particles $(P<0.05)$. In contrast, no apparent differences in cohesion value were found between untreated and mixed samples. These results further demonstrate that dynamic rheological measurement can detect subtle changes in the powder flow behaviours between untreated and mixed batches, which other methods such as CI, AOR or powder rheometry in the shear mode are unable to detect (Fig. 7).

Both SE and cohesion values for all four lactose samples decreased markedly after mechanofusion treatment, in contrast to the AOR values that could not differentiate the improvement for the L300 and S400 samples. It is notable from the cohesion values derived from the powder rheometry in its shear mode that lactose samples were very much less cohesive after mechanofusion treatment with $\mathrm{MgSt}$. As there are no significant changes in particle size, the observed changes in cohesive forces in the powder bed should be due to the modification of the surface chemistry and structure by means of the dry intensive coating. It has been reported that coating fine particles with force control agents can result in reduction in pull-off forces between fine particles [7, 21]. Moreover, lubrication of dry coating of particle surface has been demonstrated to modify the surface energy of pharmaceutical powders [22, 32]. Modification of inter-particle interactions by changing the surface chemistry via dry coating could account for our observed substantial improvements in powder flow characteristics after dry coating with $\mathrm{MgSt}$.

\section{CONCLUSIONS}

This work has shown substantial flow changes in a series of lactose monohydrate powders with different particle sizes following dry coating via the mechanofusion technique. Various powder flow evaluation methods indicated that all untreated lactose samples exhibit very poor flow properties. Particle size was to a limited extent found to affect some indices of powder flow of untreated lactose samples, with a larger size corresponding to a slightly improved flow. After the intensive mechanical dry coating with magnesium stearate, powder flow indices of all samples were substantially improved, while no dramatic changes were observed after tumbling mixing with magnesium stearate. The improvement in powder flow for lactose monohydrate samples by mechanofusion treatment was also found to be influenced strongly by their particle size. Greatest changes in poured and tapped densities were found for particles with primary particle sizes in the range 7-20 $\mu \mathrm{m}$. Angles of repose decreased dramatically after mechanofusion treatment for particles $>20 \mu \mathrm{m}$, which is attributed to the competing influence of cohesive inter-particle forces and the gravitational detachment forces. This study suggests that the particles $>20 \mu \mathrm{m}$ could exhibit good powder flow after dry coating and be suitable for the use in pharmaceutical manufacturing. To authors' knowledge, this is the first study to investigate the effect of host particle size on the improvement in powder flow by dry coating technique. The true mechanism of dry coating, the structure of the surface of these processed particles and the resulting impact on the inter-particle interactions and powder flow deserve further investigation.

Powder flow and cohesivity, reflected by their rheological properties, are in good agreement with those measured by traditional flow measurements. Powder rheometer is found to be able to detect subtle differences in powder flow behaviours because it can test samples over a wide range of stress conditions and can be a useful tool for powder flow characterization. 
Acknowledgements: Thanks to Hosokawa Micron Corporation for their help in mechanofusion operations. Q.Z. acknowledges the financial support from Faculty of Pharmacy and Pharmaceutical Sciences, Monash University in the form of faculty scholarship.

\section{REFERENCES}

[1] Abdullah E.C., Geldart D., The use of bulk density measurements as flowability indicators, Powder Technol. 102 (1999) 151-165.

[2] Adi H., Larson I., Chiou H., Young P., Traini D., Stewart P., Agglomerate strength and dispersion of salmeterol xinafoate from powder mixtures for inhalation, Pharm. Res. 23 (2006) 2556-2565.

[3] Adi H., Larson I., Stewart P., Laser diffraction particle sizing of cohesive lactose powders, Powder Technol. 179 (2007) 90-94.

[4] Alonso M., Satoh M., Miyanami K., Mechanism of the combined coating - mechanofusion processing of powders, Powder Technol. 59 (1989) 45-52.

[5] Alvarez R.C., Ageorges H., Fauchais P., Fournier P., Smith A., The effect of mechanofusion process and planetary-milling on composite powder preparation: agglomeration and fragmentation, Mater. Sci. Forum. 442 (2003) 67-72.

[6] Amidon G.E., Bergren M.S., Grant D.J.W., Marshall K., Itai S., Physical test methods for powder flow characterization of pharmaceutical materials: a review of methods stimuli to the revision process, Pharmacopeial Forum 25 (1999) 8298-8308.

[7] Begat P., Price R., Harris H., Morton D.A.V., Staniforth J.N., The influence of force control agents on the cohesive-adhesive balance in dry powder inhaler formulations, KONA Powder Part. J. 23 (2005) 109-121.

[8] Bose S., Bogner R.H., Solventless pharmaceutical coating processes: a review, Pharm. Dev. Technol. 12 (2007) 115-131.

[9] Carr R.L., Evaluating flow properties of solids, Chem. Eng. 72 (1965) 163-168.

[10] Castellanos A., The relationship between attractive interparticle forces and bulk behaviour in dry and uncharged fine powders, Adv. Phys. 54 (2005) 263-376.

[11] Chen W.L., Dave R.N., Pfeffer R., Walton O., Numerical simulation of Mechanofusion system, Powder Technol. 146 (2004) 121-136.
[12] Dave R., Chen W.L., Mujumdar A., Wang W.Q., Pfeffer R., Numerical simulation of dry particle coating processes by the discrete element method, Adv. Powder Technol. 14 (2003) 449-470.

[13] Freeman R., Measuring the flow properties of consolidated conditioned and aerated powders - A comparative study using a powder rheometer and a rotational shear cell, Powder Technol. 174 (2007) 25-33.

[14] Geldart D., Types of gas fluidization, Powder Technol. 7 (1973) 285-292.

[15] Hausner H.H., Friction conditions in a mass of metal powder, Int. J. Powder Metall. 3 (1967) 7-13.

[16] Hou H., Sun C.C., Quantifying effects of particulate properties on powder flow properties using a ring shear tester, J. Pharm. Sci. 97 (2008) 4030-4039.

[17] Iida K., Hayakawa Y., Okamoto H., Danjo K., Leuenberger H., Evaluation of flow properties of dry powder inhalation of salbutamol sulfate with lactose carrier, Chem. Pharm. Bull. 49 (2001) 1326-1330.

[18] Jiang Y.B., Matsusaka S., Masuda H., Yokoyama T., Evaluation of flowability of composite particles and powder mixtures by a vibrating capillary method, J. Chem. Eng. Jpn. 39 (2006) 14-21.

[19] Jones M.D., Price R., The influence of fine excipient particles on the performance of carrier-based dry powder inhalation formulations, Pharm. Res. 23 (2006) 1665-1674.

[20] Kim E.H.J., Chen X.D., Pearce D., Effect of surface composition on the flowability of industrial spray-dried dairy powders, Colloids Surf. B 46 (2005) 182-187.

[21] Kumon M., Machida S., Suzuki M., Kusai A., Yonemochi E., Terada K., Application and mechanism of inhalation profile improvement of DPI formulations by mechanofusion with magnesium stearate, Chem. Pharm. Bull. 56 (2008) 617-625.

[22] Kumon M., Suzuki M., Kusai A., Yonemochi E., Terada K., Novel approach to DPI carrier lactose with mechanofusion process with additives and evaluation by IGC, Chem. Pharm. Bull. 54 (2006) 1508-1514.

[23] Li Q., Rudolph V., Weigl B., Earl A., Interparticle van der Waals force in powder flowability and compactibility, Int. J. Pharm. 280 (2004) 77-93.

[24] Morton D., Dry powder inhaler formulations comprising surface-modified particles with 
anti-adherent additives, US Pat. No. 0127972 A1, 2008.

[25] Naito M., Kondo A., Yokoyama T., Applications of comminution techniques for the surface modification of powder materials, Iron Steel Inst. Jpn. Int. 33 (1993) 915-924.

[26] Pfeffer R., Dave R.N., Wei D.G., Ramlakhan M., Synthesis of engineered particulates with tailored properties using dry particle coating, Powder Technol. 117 (2001) 40-67.

[27] Pilpel N., The flow properties of magnesia, J. Pharm. Pharmacol. 16 (1964) 705-716.

[28] Raula J., Laehde A., Kauppinen E.I., A novel gas phase method for the combined synthesis and coating of pharmaceutical particles, Pharm. Res. 25 (2008) 242-245.

[29] Rowe R.C., Sheskey P.J., Owen S., Handbook of pharmaceutical excipients, Pharmaceutical Press, London, UK, 2006.

[30] Schwedes J., Review on tester for measuring flow properties of bulk solids, Granular Matter 5 (2001) 1-43.

[31] Sun C.C., Improving powder flow properties of citric acid by crystal hydration, J. Pharm. Sci. 98 (2009) 1744-1749.
[32] Swaminathan V., Cobb J., Saracovan I., Measurement of the surface energy of lubricated pharmaceutical powders by inverse gas chromatography, Int. J. Pharm. 312 (2006) 158-165.

[33] Thalberg K., Lindholm D., Axelsson A., Comparison of different flowability tests for powders for inhalation, Powder Technol. 146 (2004) 206-213.

[34] Valverde J.M., Castellanos A., Ramos A., Watson P.K., Avalanches in fine, cohesive powders, Phys. Rev. E 62 (2000) 6851-6860.

[35] Yang J., Sliva A., Banerjee A., Dave R.N., Pfeffer R., Dry particle coating for improving the flowability of cohesive powders, Powder Technol. 158 (2005) 21-33.

[36] Yokoyama T., Urayama K., Maito M., Kato M., Yokoyama T., The angmill mechanofusion system and its applications, KONA Powder Part. J. 5 (1987) 59-68.

[37] Zhou Q., Armstrong B., Larson I., Stewart J.P., Morton A.V.D., Improving powder flow properties of a cohesive lactose monohydrate powder by intensive mechanical dry coating, J. Pharm. Sci. (2009) DOI: 10.1002/jps. 21885. 